\title{
Kabiru's Value Survey: A New Optimized Method of Values Measurement
}

\author{
Kabir Bindawa Abdullahi \\ Department of Biology, Faculty of Natural and Applied Sciences, \\ Umaru Musa Yar'adua University, Katsina-Nigeria \\ Correspondence: kabir.abdullahi@umyu.edu.ng ; kabirnamallam@gmail.com \\ $(+2348065995423)$ \\ https://orcid.org/0000-0002-3810-9592
}

\begin{abstract}
Qualitative and quantitative values estimation is a crucial aspect of social data science and plays a vital role in social and psychological research. Numerous methods of personal values measurement such as Schwartz Value Survey (SVS) and its re-modified versions have been proposed and invented, but many are challenged with one or more limitations. In this article, an alternative approach in a new paradigm of values measurement called Kabiru's Value Survey (KVS) was proposed to measure the relative degree of importance or significance attached to particular value-actions of an individual(s) in a given population over a period. The methodological innovations in KVS unlike other existing methods of human value measurement include the use of habitually reported practices associated with a particular value-action in place of judging the series of Schwartz hypothetical statements, the use of multiple dependent variables rather than a single coded hypothetical statement. In terms of data analysis, a new approach of multivariate compression is introduced which merges the chain of multiple dependent variables into one coded scale. Psychometric result interpretation is also another innovative aspect of KVS methodology. Finally, the proposed methodology however solved some of the criticized limitations of the other methods of human value measurement.
\end{abstract}

Keywords: Values; Actions; Value-actions; Practice frequency; Methodology.

\section{Introduction}

When we think of our values, we reflect on what actions, activities, attitudes, and behaviors are important to us in our lives. Each of us holds and is influenced by numerous values with varying degrees of importance; the more important a value is to a person, the more likely she is to act in ways that promote the attainment of that value (Kluckhohn, 1951; Rokeach, 1973; Schwartz, 1992, 2006, 2012). Values are critical motivators of behaviors and attitudes which subsequently predict actions (Schwartz, 2012; ParksLeduc, 2015). Our attitudes are shaped and influenced by behavioral intention, which in term shapes actions (Fishbein and Ajzen, 1975). Over time, repeated habituations and engagement of value-actions is likely to strengthen values (Flouri, 1999; Sheldon, 2000; Goldberg, 2003; Hüther, 2006; Banerjee, 2008; Holmes, 2011). Values are abstract, desirable goals. Their importance is stable over time and across situations (Schwartz, 2012; Roccas, et al. 2017). Values are cognitive representations of basic motivations and are structured according to their compatibilities and conflicts (Schwartz 1992). Values are one important, the especially central component of our self and personality, distinct from attitudes, beliefs, norms, and traits.

The growing body of literature on personal values has yielded both conceptual and methodological developments. Both are reflected in the growing number of instruments developed to measure personal values. The psychometric characteristics of any specific instrument have methodological implications (Roccas, et al. 2017). Although there are other methods long existed, among the first theoretically developed and most used psychometric instruments for values measurement was the Schwartz Value Survey (Schwartz, 1992, 2006, 2012). The Schwartz Value Survey (SVS) reports the value priorities of participants explicitly, by asking them to conduct a self-reference assessment based on points-scale. Recently, about 16 
different methods were compiled to measure value priorities. Each method differs from one another in the style of questions, the number of items, response scale, and abstractness (Roccas, et al. 2017). The impacts among the instruments vary significantly, but all address the same problems of value priorities. SVS was reported to have been translated into 46 languages worldwide (Rudnev, 2011). Despite the significance of these methods especially in psychological and sociological researches, they are however being challenged with some limitations (Hood, 2003; Lee, et al. 2005; Linderman and Verkasalo, 2005; Roccas, et al. 2017).

Researchers have made enormous attempts to optimize these methods by addressing the limitations the previous instruments have, but up till now, the most recently developed psychometric methods such as the short and broad Schwartz value Survey (SB SVS) of Sekerdej and Roccas (2016), Ten Item Value Inventory (TIVI) by Sandy et al. (2016), Twenty Item Value Inventory (TwIVI) by Sandy et al. (2016), and Animated Values Instrument (AVI) by Collins et al. (2017) have failed to address some of the limitations. The central focus of these interested researchers was to optimize the instrument of data collection for a low number of questions, fewer items, and simple instruction, clarity, and style of questioning (Roccas et al. 2017). These methods neglected the most essential but covert aspect of value theories and methodology such as the issue of value-action gab, variety in methods of data collection and data analysis, a shift from conventional ranking and rating approach to a more universal and more measurable approach of importance measurement, methodological broadness in scope and applications. Therefore, any future work is worth a solution to these problems. Now, our solution is to rethink logically and reflect on the theoretical explanations.

In this article, a new alternative methodological approach for human value measurement called Kabiru's value survey (KVS) is proposed that theoretically and conceptually takes into consideration some of these unsolved limitations. KVS is however based on the use of reported practices of value-actions of a particular value type. It varies in its methods of survey data collection and psychometric data analysis. It shifts from a conventional ranking and rating approach to a more universal and descriptive approach of value measurement.

\section{Methods of Human Value Measurement}

This is a short scan review of some commonly used methods of human values measurements and an evaluation of their limitations. The essence of this section is to present and remind the reader of the methodological scopes and limitations of some other existing methods of human value measurement.

\section{Human Value Measurement}

The research literature is rife with measures of values, attesting to the importance that the values construct has gained in the last decades. The instruments developed to measure human values correspond to the definition of values as desirable goals that serve as guiding principles (Roccas, et al. 2017). A comprehensive report presented by Roccas, et al. (2017) presented an up-to-date list of 16 methods and instruments used for psychometric value measurement. He categorized them into panels based on the reference authors: Panel-A was the seminal Rokeach Value Survey (RVS, Rokeach, 1973). Panel-B was the list of instruments developed by Schwartz over time. Panel-C was the instrument developed by other researchers who draw on Schwartz's theory and are designed to measure the same value system. Finally, Panel-D was the list of measures that do not draw on Schwartz's model but correspond to the same definition of values. Because of the space constraint, I shall not present the description of these methods individually, but all the methods address the following methodological issues:

Data collection instrument: A questionnaire is a typically used method of data collection. Most questionnaires have the following feature: The methods measure the abstract or concrete nature of values. The number of items is determined by the number of values and their specific items considered. Depending on the method, it ranges from 10-105 items. Rating, ranking, and pairwise comparison approaches are employed to measure the respondents' judgment. In the rating approach, value questionnaires ask participants to consider each item independently of how they view the other items and rate its importance on established scale points labeled as 7 (for supreme importance), 6 (for very important), 5, 4 (unlabeled), 3 (for important), 2, 1 (unlabeled), 0 (for not important), -1 (for opposed to my values). In the ranking approach, respondents are asked to compare the given items to each other and to hierarchically order them 
by importance relative to one another. In the pairwise comparison approach, respondents are asked to compare two items which one most important to him (Roccas, et al. 2017).

The instrument for data analysis: In psychometric analysis means of scores for each value item express the result of value priorities (Schwartz, 1992; Linderman and Verkasalo, 2005). The correlation method is the most used method of statistical analysis of the calculated results of values priorities. (Oishi, et al. 1998; Schwartz, et al. 2001; Linderman and Verkasalo, 2005).

\section{Limitations}

Previous works of literature emphasized their critics regarding the disadvantages the use of ranking scale is, and sometimes the rating scale, the level of abstraction, the length and broadness of instruments and its questionnaire items, the response format and response scale, the cross-cultural validation of the measurement instruments, the nature of the response scores and the limit of data analysis, the difficulties of answering the questionnaire question (Hood 2003; Lee et al. 2005; Linderman and Verkasalo, 2005; Roccas, et al. 2017). However, the recent methodologies have addressed most of these limitations (Roccas, et al. 2017). I further added the following limitations that were not noticed and considered. These are:

Response scale: Although the rating scale is the most adopted in almost all the methods. The assumption that equal gaps of importance between one attributes of importance to the other would ensure a fixed distribution for all respondents (Roccas, 2017). But understanding the strength and magnitude between each of the gab may have a relation with the age, experience, gender, socialization, and geographical location, etc. of the individual respondent. However, the most important aspect of individuals' variations is measured at this point. Therefore, the rating scale is insufficient to address this issue. The rating scale provides only abstract meaning about the abstract variations that exist from one rated scale point to the others.

Result's Ambiguity: The value priority result is the mean of scores of individuals' responses. The results are, in some cases, ambiguous. It is ambiguous in the sense that the method may fail to provide consistent and valid results. For instance, suppose the scale points 2, 1, and -1 are the only responded items in the Schwartz value survey (SVS) method by 20, 50, and 90 respondents respectively, the mean score would be equal to zero, that means no values (importance) at all, while it is invalid to accept.

Value-action gab: The methods did not consider and address the issue of value-actions gab, but only the instrumental state of values (an abstract concept) is considered. The space that occurs when the values (personal and cultural) or attitudes of an individual do not correlate to his or her action is what the issue of value-action gab addressed. The theory of reasoned action states that behavioral intention is dependent on attitudes surrounding that behavior and social norms (Fishbein and Ajzen, 1975).

Data collection methods: A questionnaire is the only method adopted for data collection. Thus, experimental, interview, and other methods cannot be applied.

Simplicity and time efficiency: Rating a question requires more time and reasoning because the response did not form a component of behavioral reflexes.

Methodological broadness in scope and applications: The value for material objects is neglected. For instance, values for our biodiversity, a specific object. This limited the methodological applications in other fields of studies such as ethnobotany and others.

\section{The New Proposed Method, Kabiru's Value Survey}

\section{Theoretical frameworks}

The Kabiru's value survey is principally based on human value-related theories such as Fishbein and Ajzen (1975); Holmes (2011); Schwartz (2006, 2012); Parks-Leduc (2015). Human value scholars have a common consensus that our values are the guiding forces that shape and serve as a predictor of our actions. 
Suppose that in a culturally dynamic population of individuals, a set of value-actions were allowed without restriction and limitation to be practiced, we can establish the following facts about these valueactions:

i. The choice or selection of value-actions: Some individuals may choose to practice them (i.e. recognize them valuably important or significant), while others may not practice. This freedom of self-direction forms among the basic features of human values (Schwartz, 2006, 2012; Holmes, 2012).

ii. The preferences for values items and actions: What follows the choice or selection of valueaction is the preferences over the selections made. The practitioners of such value-actions may choose to practice all or select among others. This depends on their selective preferences for each valuable action. The self-directional features of values direct our choice or selection of actions and events (Schwartz, 2006, 2012). Bilsky, Janik \& Schwartz, (2011); Davidov, et al., (2008); Schwartz, (2006) added that the existence of value across different cultural population and entities determine its universality. Therefore, the number of practiced value items or categories is an important index of value diversity within the value domain.

iii. The degree of importance: The practitioners of such value-actions may practice with a different degree (frequency) of importance or significance relative to others. This depends on their practical preferences for each value-action. Studies and reports by Flouri (1999); Sheldon (2000); Goldberg (2003); Banerjee (2008) Hüther (2006); and Holmes (2011) reported that repeated habituations and engagement of value-actions is likely to strengthen values. The ordering of values by importance relative to others is recognized as one of the basic features of value priorities (Schwartz, 2006, 2012). Therefore, the frequency of practices of particular value-actions relative to others indicates a relative degree of importance and strength of that particular valuable action.

iv. The population intensity and values dynamics: Over time, some among the practitioners may decline to practice, and some among the non-practitioners may accept to practice. Our values therefore not only change at different points of our lives but also day-to-day (Holmes, 2011). Moreover, population changes (increase or decline) over time may likely to diminish or promote the intensity and representation of such value-actions within the population. Practitioners from different populations may have the same frequency of practice for a particularly valuable activity, but the frequency of practitioners concerning the population (practitioners' intensity) may significantly differ. Although studies by Bilsky, Janik \& Schwartz (2011); Davidov et al. (2008); Schwartz (2006) shows that values are cross-culturally the same, variation exists between groups. The point raised here is not the inter-cultural variations, but the intensity of value level in a population, which is expected to change with time and population growth. Therefore, the number of practitioners for a particular value-actions in a population is an important factor.

In a general sense, the method of values measurement can be expressed as the measure of the relative degree of importance or significance (expressed by frequency factors of variables) attached to particular value-actions of an individual(s) in a given population over a period. And the value distribution in different categories determines its universality. From these facts, important parameters and variables were extracted for conceptualization.

\section{Conceptual framework}

The conceptual framework in Kabiru's value survey methodology expresses the variables, the structure, and design of survey instruments, survey data collection and psychometric data analysis, and psychometric result interpretations.

\section{The survey instrumentation}

Before the design of a survey instrument (e.g., questionnaire, interview, behavioral observations, etc.), the following variables are considered: 


\section{The variables}

1. The independent variables are the value-actions in questions. Table A (of appendix A) highlighted examples of value-actions of some human values.

2. The dependent variables are the frequencies of value-actions (i.e., habitually reported practices related to a particular personal value). Each dependent variable may have at least more than one level arranged in a defined order. Two types of dependent variables are identified as primary and secondary dependent variables.

i. The primary dependent variables: these are the top and main events of the value-actions which are habitually practiced.

ii. The secondary dependent variables: these are the supporting events that link to the main event of the value-actions which are habitually practiced. They can take $\mathrm{N}$-orders of proceeding links.

The primary dependent variables can have more than 9 levels of items, but in this application, it is limited to the selection of only 5 levels), while the secondary dependent variables cannot have more than 9 levels. Table B1-B3, and Fig. B (of appendix B) provided examples.

\section{The operational definition of terms}

Value-actions: Value-actions are the action-state driven by our values. Each value transcends specific action, but it is recognized by sets of specific value-actions (Schwartz, 2006, 2012; Holmes, 2011). Table A (of appendix A) presented some examples of specific values and their possible value-actions. From Table A, we can understand that attaching importance to a specific value type initiates the development of attitudes and behaviors that stimulates the onsets of several behavioral actions. For instance, recognizing the significance of our health stimulates us for a routine medical check-up, dietary control, exercise regularly, hygiene, sanitation, drug administrations, avoid consuming harmful products, abstain from drug abuse every, etc. The average score of each value action expresses the absolute value score.

Events: These are descriptive terms (qualities) that define the occurrence of value-actions by a factor. Two approaches can be used as follows:

i. $\quad$ Calendar Approach: This approach employs the use of calendar attributes (events), such as "daynight, daylight, week, month, year. These attributes of the calendar should be considered as the primary dependent variables (main event's practice). The approach of using these events remains to fix and serves as a reference guide upon which all other secondary dependent variables (supporting event's practices) are linked to. Table 1 and Fig. B (of appendix B) presented some examples.

ii. Clock Approach: In this case, clock events (as the supporting event's practices) such as hours, minutes, and seconds are used. In choosing this approach, one should note that except for biological actions, almost all forms of human value-actions are rarely repeated continuously on every clock time basis. Table 2 presented some examples. 
Table 1: Calendar approach values frequency events

\begin{tabular}{|c|c|c|c|}
\hline \multicolumn{2}{|c|}{ Practice (action) frequency } & \multirow{2}{*}{$\begin{array}{c}\begin{array}{c}\text { Scaling and } \\
\text { RERN }\end{array} \\
1\end{array}$} & \multirow{2}{*}{$\begin{array}{c}\text { RERN Identity } \\
\begin{array}{c}(\boldsymbol{R} \boldsymbol{E} \boldsymbol{R} \boldsymbol{N})_{\boldsymbol{i}} \\
(R E R N)_{1}\end{array}\end{array}$} \\
\hline Every & Year & & \\
\hline & Month & 2 & $(R E R N)_{2}$ \\
\hline & Week & 3 & $(R E R N)_{3}$ \\
\hline & Daylight or Day-night & 4 & $(R E R N)_{4}$ \\
\hline & Day and night & 5 & $(R E R N)_{5}$ \\
\hline \multirow[t]{5}{*}{ Every } & 5 days and nights & 4.1 & $(R E R N)_{5,1}$ \\
\hline & 4 days and nights & 4.3 & $(R E R N)_{5,2}$ \\
\hline & 3 days and nights & 4.5 & $(R E R N)_{5,3}$ \\
\hline & 2 days and nights & 4.7 & $(R E R N)_{5,4}$ \\
\hline & 1 day and night & 4.9 & $(R E R N)_{5,5}$ \\
\hline \multirow[t]{3}{*}{ Every } & 6 weeks & 2.3 & $(R E R N)_{3,1}$ \\
\hline & 4 weeks & 2.6 & $(R E R N)_{3,2}$ \\
\hline & 2 weeks & 2.9 & $(R E R N)_{3,3}$ \\
\hline \multirow[t]{5}{*}{ Every } & 5 daylights, $0-3$ times & 3.11 & $(R E R N)_{4,1,1}$ \\
\hline & 4 daylights, 4-6 times & 3.33 & $(R E R N)_{4,2,2}$ \\
\hline & 3 daylights, 7-9 times & 3.55 & $(R E R N)_{4,3,3}$ \\
\hline & 2 daylights, $10-12$ times & 3.77 & $(R E R N)_{4,4,4}$ \\
\hline & 1 daylights, $13-15$ times & 3.99 & $(R E R N)_{4,5,5}$ \\
\hline
\end{tabular}

Event's practice frequency: These are measurable quantities that estimate the relative occurrence of a particular value-action. Frequencies by certain factors (e.g., 'about every event', for/of several repeated events) of an individual's practices or actions for particular value items in question are questioned, recorded, or ask in the case of a questionnaire, experimentation, or interview methods respectively. The assumption here is that, for any value-action that is habitually repeated every day and night reserve the highest degree of importance upon which other event's practices are related. The least relative order of importance is the yearly habituation of value-actions. Table 1-2 and Fig. B (of appendix B) presented some examples.

Established categories or strata: The issue of values universality necessitates the consideration of established categories or strata. Universality in the sense that is how uniform values are across different cultures, ethnicities, ages, social status, etc.

Activists: Activists refer to the active respondents or informants of a target population who are engaged in particular value-actions. 
Table 1: Calendar approach of values frequency events (Continuation....)

\begin{tabular}{|c|c|c|c|}
\hline \multicolumn{2}{|c|}{ Practice (action) frequency } & \multirow{2}{*}{$\begin{array}{c}\text { Scaling and } \\
\text { RERN } \\
3.8\end{array}$} & \multirow{2}{*}{$\begin{array}{c}\text { RERN } \\
\text { identity } \\
(\boldsymbol{R} \boldsymbol{E} \boldsymbol{R} \boldsymbol{N})_{\boldsymbol{i}} \\
(R E R N)_{4,4}\end{array}$} \\
\hline In every day* & All the time/situation/case & & \\
\hline & Most of the time/situation/case & 3.6 & $(R E R N)_{4,3}$ \\
\hline & Less of the time/situation/case & 3.4 & $(R E R N)_{4,2}$ \\
\hline & Rare of the time/situation/case & 3.2 & $(R E R N)_{4,1}$ \\
\hline & All the situation, $11-15$ times & 3.89 & $(R E R N)_{4,4,3}$ \\
\hline & All the situation, 6-10 times & 3.86 & $(R E R N)_{4,4,2}$ \\
\hline & All the situation, 1-5 times & 3.83 & $(R E R N)_{4,4,1}$ \\
\hline & In most of the situation, $11-15$ times, & 3.69 & $(R E R N)_{4,3,3}$ \\
\hline & Most of the situation, 6-10 times & 3.66 & $(R E R N)_{4,3,2}$ \\
\hline & Most of the situation, 1-5 times & 3.63 & $(R E R N)_{4,3,1}$ \\
\hline & Less of the situation, $11-15$ times, & 3.69 & $(R E R N)_{4,3,3}$ \\
\hline & Less of the situation, 6-10 times & 3.66 & $(R E R N)_{4,3,2}$ \\
\hline & Less of the situation, 1-5 times & 3.63 & $(R E R N)_{4,3,1}$ \\
\hline & Rare of the situation, $11-15$ times & 3.29 & $(R E R N)_{4,1,3}$ \\
\hline & Rare of the situation, $6-10$ times & 3.26 & $(R E R N)_{4,1,2}$ \\
\hline & Rare of the situation, 1-5 times & 3.23 & $(R E R N)_{4,1,1}$ \\
\hline & In most of the situation, $11-15$ times, for 3 hours & 3.899 & $(R E R N)_{4,3,3,3}$ \\
\hline & Most of the situation, 6-10 times, for 2 hours & 3.866 & $(R E R N)_{4,3,2,2}$ \\
\hline & In most of the situation, $1-5$ times, for 1 hour & 3.833 & $(R E R N)_{4,3,1,1}$ \\
\hline
\end{tabular}

*The practice frequency can take any other event's factor such as: In every year, every month, every week, every day and night.

Table 2: Clock Approach of values frequency events

\begin{tabular}{llcc}
\hline Practice (action) frequency & $\begin{array}{c}\text { Scaling and } \\
\text { RERN }\end{array}$ & $\begin{array}{c}\text { RERN identity } \\
(\boldsymbol{R E R} \boldsymbol{R})_{\boldsymbol{i}}\end{array}$ \\
\hline Every & Hour & 4.3 & $(R E R N)_{5,1}$ \\
& Minute & 4.6 & $(R E R N)_{5,2}$ \\
& Second & 4.9 & $(R E R N)_{5,3}$ \\
Every & 21 hours & & $(R E R N)_{5,1,1}$ \\
& 16 hours & 4.31 & $(R E R N)_{5,1,2}$ \\
& 11 hours & 4.33 & $(R E R N)_{5,1,3}$ \\
& 6 hours & 4.35 & $(R E R N)_{5,1,4}$ \\
Every & 1 hour & 4.37 & $(R E R)_{5,1,5}$ \\
& 9 minutes, $21-30$ times & 4.39 & $(R E R N)_{5,2,1,3}$ \\
& 6 minutes, 11-20 times & 4.639 & $(R E R N)_{5,2,2,2}$ \\
& 2 minutes, 0-10 times & 4.666 & $(R E R N)_{5,2,3,1}$ \\
\hline
\end{tabular}




\section{The structure of the survey instrument}

The structure of KVS is the proceeding order of relationship that link primary dependent variables and the $\mathrm{N}$-order of secondary dependent variables of a particular value-action, such that:

- Each level of the primary dependent variable is linked to any level (as a subset) of the first order secondary dependent variable,

- Each level of the first order secondary dependent variable is linked to any level (as a subset) of the second-order secondary dependent variable,

- Each level of the second-order secondary dependent variable can link to any level (as a subset) of the third-order secondary dependent variable, and the chain goes this way.

Each dependent variable may have at least more than one level (as subsets) arranged in defined ranking order. The survey instrument comprised of a proceeding order of frequencies of habitually reported practices of a particular value-action in question.

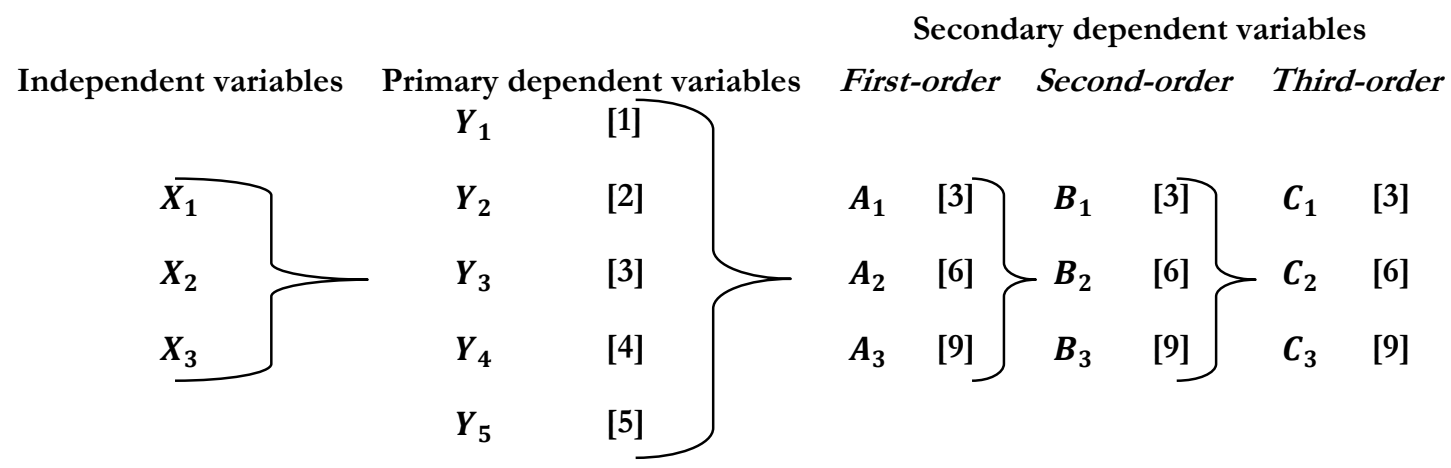

Figure 1: Conceptual relationship among the variables in KVS methodology

\section{Scaling of responses of the survey instrument}

This is comprised of the assignment of numerical numbers that represent the magnitude of levels of the primary dependent variables and the $\mathrm{N}$-order of secondary dependent variables of a particular valueaction.

The systematic order of scaling (ranking) in ascending manner must begin from the event with the least (lowest) frequency, then to the maximum (highest) frequency (See Table 1 and 2, and Fig. B). The numerical value assigned to each frequency event is called the event's rank number $(E R N)$.

Event's rank numbering involves $\mathrm{N}$-gab scaling of the dependent variables. For instance, one-gab scaling $(1,2,3,4,5,6,7,8,9)$; two-gab scaling $(2,4,6,8)$ or $(1,3,5,7,9)$; three-gab scaling $(3,6,9)$; fourgab scaling $(4,8)$, can be adopted, depending on the number of levels of each secondary dependent variable. The scaling for $x E R N$ of the primary dependent variables has no limited range, but for N-order secondary dependent variables have a limit of at most 1-9 value range.

It should be noted that the scale ranking of the primary dependent variables is always fixed for any research design. A one-gab scaling $(1,2,3,4$, and 5$)$ must be always assigned to any event that is habitually practiced every year, every month, every week, every daylight or every day-night, and every day and night respectively. Zero (0) scaling of the levels of the primary dependent variable is assigned where the valueaction is never habitually practiced.

\section{Multivariate compression of the survey responses}

This is an equation that merges into one the assigned numerical scale of the primary dependent variable and the $\mathrm{N}$-order of secondary dependent variables of a particular value-action.

In the incidence where additional secondary dependent variables are considered, the resultant event's rank number (RERN) of the multiple variables are analyzed by the equation (1) below. The number 
of digits of the RERN tells the number of dependent variables composed. A subscript $i$ in $(R E R N)_{i}$ is any defined symbol that assigns the identity of the observed RERN. Tables 1 and 2 presented some examples.

$$
(R E R N)_{i}=\left(\frac{(F E R N)_{p}}{1}+\frac{(F E R N)_{s}}{10}+\frac{(S E R N)_{s}}{100}+\ldots \ldots \ldots \frac{(x E R N)_{s}}{10^{y}}\right)-1
$$

Where:

$y=$ a count of series from zero to infinity $(y=0,1,2, \ldots \infty)$

$10 y=$ Factorial fractions, which is progressive by $y$

$i=$ identity of the observed coded scales or RERN

$R E R N=$ Resultant event's rank number

$(F E R N)_{p}=$ Event's rank number of the primary dependent variable.

$(F E R N)_{s}=$ Event's rank number of the first-order secondary dependent variable.

$(S E R N)_{s}=$ Event's rank number of the second-order secondary dependent variable.

$(x E R N)_{s}=$ Event's rank number of the last-order secondary dependent variable.

\section{Psychometric data analysis}

In this subsection of the paper, the emphasis is on the development of a psychometric index that integrates and associates the survey data into a psychologically meaningful result. In this case, the actionvalue and action-value diversity index were proposed to measure value priority scores of particular value items in questions.

\section{Value priority Scores}

Action-value index or Activity-value index (AVI): This is an equation that measures the relative degree of importance (by frequency factor) attached to particular value-actions of an individual(s) in a given population over a period. The results of action-value express the value priority score which ranges from 0 to 1.

Per single respondent:

$$
A V I=\frac{(R E R N)_{i}}{5}
$$

The unit is expressed as practice per individual $\left(\mathrm{PI}^{-1}\right)$.

Perpopulation:

$$
A V I=\frac{1}{5 \times N p} \sum_{1}^{i}(R E R N \times n a)_{i}
$$

The unit is expressed as practice per population ( $\left.\mathrm{PP}^{-1}\right)$.

Per individual and per population:

$$
A A V I=\frac{1}{n v i} \sum_{1}^{n v i}(A V I)
$$

The unit is expressed as practice per population $\left(\mathrm{PP}^{-1}\right)$.

Where: 
$A A V I=$ average action-value index

$n v i=$ number of value items

$i=$ identity of the observed coded scales or RERN

$R E R N=$ resultant event's rank number

$n a=$ total number of event activists

$N a$ : total number of population activists

$N p$ : total number of the population sample

$5=$ is the maximum event's rank number (i.e. of every day and night frequency of value-actions

Action-value diversity index or Activity-value diversity index (AVDI): Action-value diversity index (AVDI) refers to the measure of the universality of values as its existence in different aspects of established categories. It can be express by equation 5 .

Where:

$$
A V D I=\frac{1}{N C} \sum_{1}^{N C}(A V I)
$$

$N C=$ number of established categories

\section{Psychometric result interpretation}

Table 3 provided symmetric ranges of value priority scores (of action-value index and action-value diversity index) for drawing a psychologically simple conclusion about values.

Table 3: Ranges of value status and interpretations

\begin{tabular}{lll}
\hline Value Status Ranges & $\begin{array}{l}\text { Action-value Index } \\
\text { (AVI) }\end{array}$ & $\begin{array}{l}\text { Action-value Diversity } \\
\text { Index (AVDI) }\end{array}$ \\
\hline 0 & No & No \\
$>0-0.20$ & Low & Low \\
$0.21-0.40$ & Moderate & Moderate \\
$0.41-0.60$ & High & High \\
$0.61-0.80$ & Extreme & Extreme \\
$0.81-1.00$ & Extraordinary & Extraordinary \\
\hline
\end{tabular}

\section{Methodological innovations of KVS}

The primary innovative features of KVS that distinguish it from other existing methods of human value measurement (such as SVS methods) includes the following:

i. The primary innovation in KVS is the use of habitually reported practices instead of a series of hypothetical statements.

ii. Secondly, the use of multiple dependent variables rather than a single coded hypothetical statement.

iii. Thirdly, a new approach of multivariate compression is introduced which merges the chain of multiple variables into one coded scale.

iv. Lastly, psychometric result interpretation is also another innovative aspect of KVS methodology. 


\section{Methodological comparisons}

Table 4 presented the comparisons between KVS and the most adopted methods of human value measurement (i.e., the SVS methods) based on some important criteria such as simplicity, specificity, the broadness of the survey instrument, as well as the method of data collection, and psychometric data analysis.

The result of the comparison shows that the KVS method has some distinguishing advantages over the SVS method in terms of simplicity (for the questions, for the response scales, for everyone to understand and recall the which response scale to select), specificity (to which respondent, to which valueaction is practice), broadness (in scope and applications) of the measurement instruments for data collection, psychometric data analysis, and psychometric result interpretation. The approach employed in the KVS method is theoretically and conceptually oriented, and has solved some of the criticized limitations of other methods of human value measurement.

Table 4: Comparisons between Kabiru's Value Survey (KVS) and Schwartz Value Survey (SVS) Methods

\begin{tabular}{|c|c|c|}
\hline Criteria & KVS Method & SVS Methods \\
\hline $\begin{array}{l}\text { Number of } \\
\text { selectable } \\
\text { response scales }\end{array}$ & $\begin{array}{l}\text { A single or chain of multiple } \\
\text { dependent variables (response scales) } \\
\text { can be selected. }\end{array}$ & $\begin{array}{l}\text { A single dependent variable } \\
\text { (response scale) is only selected from } \\
\text { a judged hypothetical question. }\end{array}$ \\
\hline $\begin{array}{l}\text { Multivariate } \\
\text { compression of } \\
\text { the response } \\
\text { scale }\end{array}$ & $\begin{array}{l}\text { A chain of multiple dependent } \\
\text { variables (response scales) is } \\
\text { compressed into one coded scale } \\
\text { point. }\end{array}$ & $\begin{array}{l}\text { - A multivariate compression of the } \\
\text { response scale is not required. }\end{array}$ \\
\hline $\begin{array}{l}\text { Qualitative state } \\
\text { of the response } \\
\text { scale }\end{array}$ & - Action-state. & - Instrumental and abstract state. \\
\hline $\begin{array}{l}\text { Response scale } \\
\text { coding }\end{array}$ & $\begin{array}{l}\text { - Dependent variables (of frequency } \\
\text { events) are coded by ranking scale. }\end{array}$ & $\begin{array}{l}\text { - Dependent variables (of hypothetical } \\
\text { statements) are coded by a rating } \\
\text { Likert scale. }\end{array}$ \\
\hline $\begin{array}{l}\text { Cognition of } \\
\text { the response } \\
\text { scale }\end{array}$ & $\begin{array}{l}\text { - The response scale is universal, simple } \\
\text { to understand, and recall by the } \\
\text { respondents. }\end{array}$ & $\begin{array}{l}\text { The response scale is not universal, } \\
\text { difficult to understand, and recall by } \\
\text { the respondents. }\end{array}$ \\
\hline $\begin{array}{l}\text { Instruction of } \\
\text { the survey } \\
\text { instrument }\end{array}$ & $\begin{array}{l}\text { - Respondents score the importance of } \\
\text { each value item "as a HABITUAL } \\
\text { ACTION in his/her life" }\end{array}$ & $\begin{array}{l}\text { - Respondents rate the importance of } \\
\text { each value item "as a GUIDING } \\
\text { PRINCIPLE in his/her life" }\end{array}$ \\
\hline $\begin{array}{l}\text { Value-action } \\
\text { gab }\end{array}$ & $\begin{array}{l}\text { - Is considered and addressed, because } \\
\text { the action-state of values is } \\
\text { considered. }\end{array}$ & $\begin{array}{l}\text { - It is not considered and addressed, } \\
\text { because the instrumental state of } \\
\text { values (an abstract concept) is } \\
\text { considered. }\end{array}$ \\
\hline $\begin{array}{l}\text { Data collection } \\
\text { methods }\end{array}$ & $\begin{array}{l}\text { - It can be by many methods such as } \\
\text { questionnaires, experimental } \\
\text { observation, and interviews. }\end{array}$ & $\begin{array}{l}\text { - It is only by the questionnaire } \\
\text { method. }\end{array}$ \\
\hline $\begin{array}{l}\text { Psychometric } \\
\text { data analysis }\end{array}$ & $\begin{array}{l}\text { - Is the relative mean scores of all the } \\
\text { coded scales of the habitually reported } \\
\text { practices }\end{array}$ & $\begin{array}{l}\text { - Is the none relative mean scores of } \\
\text { all the responded Likert scale codes. }\end{array}$ \\
\hline $\begin{array}{l}\text { Unit of } \\
\text { measurement }\end{array}$ & $\begin{array}{l}\text { Practice per individual }\left(\mathrm{PI}^{-1}\right) \text { or } \\
\text { practice per population }\left(\mathrm{PP}^{-1}\right) \text { is the } \\
\text { used unit. }\end{array}$ & - No unit is defined. \\
\hline $\begin{array}{l}\text { Result } \\
\text { interpretation }\end{array}$ & $\begin{array}{l}\text { - It ranges from } 0 \text { to } 1 \text { and is sub- } \\
\text { grouped into psychometrically } \\
\text { interpretable ranges. }\end{array}$ & $\begin{array}{l}\text { - It ranges from -1 to 7, and } \\
\text { psychometric interpretation is not } \\
\text { provided. }\end{array}$ \\
\hline
\end{tabular}




\begin{tabular}{|c|c|c|}
\hline $\begin{array}{l}\text { Result } \\
\text { ambiguity }\end{array}$ & - Is yet to be observed or projected. & - Is projected as in this case below* \\
\hline $\begin{array}{l}\text { Simplicity and } \\
\text { time efficiency }\end{array}$ & $\begin{array}{l}\text { Requires less time to respond to the } \\
\text { survey items, because the response } \\
\text { may have developed some behavioral } \\
\text { instinct or reflexes. }\end{array}$ & $\begin{array}{l}\text { Requires more time to respond to } \\
\text { the survey items, because rating it } \\
\text { requires reasoning. }\end{array}$ \\
\hline $\begin{array}{l}\text { Methodological } \\
\text { broadness }\end{array}$ & $\begin{array}{l}\text { It is broad in scope and applications. } \\
\text { For instance, material values for a } \\
\text { particular object is considered, this } \\
\text { can permit other fields of studies such } \\
\text { as ethnobotany to apply. }\end{array}$ & $\begin{array}{l}\text { - Other fields of studies are ignored } \\
\text { because material values for a } \\
\text { particular object are not considered } \\
\text { within the scope. }\end{array}$ \\
\hline $\begin{array}{l}\text { Theoretical } \\
\text { considerations }\end{array}$ & $\begin{array}{l}\text { - The variables and their interactions } \\
\text { reflect the theoretical concepts about } \\
\text { values, such include below** }\end{array}$ & $\begin{array}{l}\text { - The method did not address some } \\
\text { theoretical issues, such include } \\
\text { below** }\end{array}$ \\
\hline
\end{tabular}

*Ambiguous in the sense that the method may fail to provide consistent and valid results. For instance, if scale points 2,1 , and -1 are the only responded points in the SVS method by 20, 50, and 90 respondents respectively, the mean score would be equal to zero, which means no values score at all, while it is invalid to accept.

**(1) Value-action gab (Fishbein and Ajzen 1975), (2) Repeated habituations and engagement in value-actions as a strengthening factor of values (Flouri 1999; Sheldon 2000; Goldberg 2003; Hüther 2006; Banerjee 2008; and Holmes 2011), (3) Actions as driven forces and end-state of values (Holmes 2012; Schwartz 2006, 2012), (4) Value dynamics: that values changes in all our day-to-day lives (Holmes 2012).

\section{Limitations of KVS}

i. It is suitable for habitually reported practices of value-actions, otherwise, none-habitually reported practices cannot be measured appropriately.

ii. The number of levels for each secondary dependent variable must not be greater than nine (9) items.

\section{Conclusion}

KVS is a methodology that covers the design of the survey instrument, the analysis of survey data, and the psychometric result interpretations. It is a new paradigm of values measurement that estimates the relative degree of importance or significance attached to particular value-actions of an individual(s) in a given population over a period. The methodological innovations in KVS unlike other existing methods of human value measurement include the use of habitually reported practices as opposed to the series of Schwartz items which invite respondents to judge 'how similar (alike) they are to a hypothetical person with certain outlooks on life, the use of multiple dependent variables rather than a single coded hypothetical statement. In terms of data analysis, a new approach of multivariate compression is introduced which merges the chain of multiple dependent variables into one coded scale. Psychometric result interpretation is also another innovative aspect of KVS methodology. Finally, the proposed methodology however solved some of the criticized limitations of other methods of human value measurement.

\section{Recommendations}

This paper recommends that the survey instrument developed following KVS methodology should be subjected to validity and reliability tests before it can be applied on any suitable problem.

\section{References}

Banerjee, R., and Dittmar, H. (2008). Individual differences in children's materialism: the role of peer relations. Personality and Social Psychology Bulletin, 31(1), 17-31.

Bilsky, W., Janik, M., \& Schwartz, S. H. (2011). The structural organization of human values: Evidence from three rounds of the European Social Survey (ESS). Journal of Cross-Cultural Psychology, 42(5), 759-776. doi: 10.1177/0022022110362757. 
Collins, P. R., Lee, J. A., Sneddon, J. N., \& Döring, A. K. (2017). Examining the consistency and coherence of values in young children using a new Animated Values Instrument. Personality and Individual Differences, 104, 279-285.

Davidov, E., Schmidt, P., \& Schwartz, S. H. (2008). Bringing values back in the adequacy of the European Social Survey to measure values in 20 countries. Public Opinion Quarterly, 72(3), 420-445.

Fishbein, M., Ajzen, I. (1975). Belief, attitude, intention, and behavior: An introduction to theory and research. Reading: MA: Addison-Wesley.

Flouri, E. (1999). An integrated model of consumer materialism: can economic socialization and maternal values predict materialistic attitudes in adolescents? Journal of Socio-Economics, 28 (6), 707-724.

Goldberg, M. E., Gorn, G. J., Peracchio, L. A. and Bamossy, G. (2003). Understanding materialism among youth. Journal of Consumer Psychology, 13(3), 278-288

Holmes, T., Blackmore, E., Hawkins, R., and Wakeford, T. (2011). The Common Cause Handbook, Public Interest Research Centre Publishers, United Kingdom, pp. 30. ISBN: 978-0-9503648-7-2.

Hood, Jacqueline. (2003). The Relationship of Leadership Style and CEO Values to Ethical Practices in Organizations. Journal of Business Ethics, 43, 263-273.

Hüther, G. (2006). Neurobiological approaches to a better understanding of human nature and human values. The Journal for Transdisciplinary Research in Southern Africa, 2(2), 331-343.

Kluckhohn, C. (1951). Values and value-orientations in the theory of action: An exploration in definition and classification. In T. Parsons \& E. Shils (Eds.), Toward a general theory of action (pp. 388-433). Cambridge. MA: Harvard University Press.

Lee, J. A., Soutar, G. N., Louviere, J. J. (2005). An Alternative Approach to Measuring Schwartz's Values: The Best-Worst Scaling Approach". Journal of Personality Assessment, 90, 335-347

Lindeman, M., Verkasalo, M. (2005). Measuring Values With the Short Schwartz's Value Survey". Journal of Personality Assessment, 85: 170-178.

Parks-Leduc, L., Feldman, G., and Bardi, A. (2015). Personality Traits and Personal Values: A MetaAnalysis. Personality and Social Psychology Review, 19(1), 3-29. doi: 10.1177/1088868314538548.

Roccas, S., Sagiv, L., \& Navon, M. (2017). Methodological Issues in Studying Personal Values. Values and Behavior, 15-50. doi:10.1007/978-3-319-56352-7_2.

Rokeach, M. (1973). The nature of human values. New York: Free press.

Rudnev, M. (2011). Constraints and opportunities of 10 Schwartz Value Survey items in the World Values Survey. ESR A Conference, 20 July 2011. Lausanne, Switzerland.

Sandy, C. J., Gosling, S. D., Schwartz, S. H., \& Koelkebeck, T. (2016). The development and validation of brief and ultra-brief measures of values. Journal of Personality Assessment, 1-11.

Schwartz, S. H. (1992). Universals in the content and structure of values: Theoretical advances and empirical tests in 20 countries. Advances in Experimental Social Psychology, 25(1), 1-65.

Schwartz, S. H. (2005). Robustness and fruitfulness of a theory of universals in individual human values. In A. Tamayo \& J. B. Porto (Eds.), Valores ecomportamentonasorganizaçAtoes $[V$ alues and behavior in organizations] (pp. 56-95). Petrópolis: Vozes.

Schwartz, S. H. (2006). Les valeurs de base de la personne: Theorie, mesures et applications [Basic human values: Theory, measurement, and applications]. Revue Fran_caise de Sociologie, 47, 249-288.

Schwartz, S. H. (2012). An overview of the Schwartz theory of basic values. Online Reading in Psychology and Culture, 2(1), Article no11.

Sekerdej, M., \& Roccas, S. (2016). Love versus loving criticism: Disentangling conventional and constructive patriotism. British Journal of Social Psychology, 55(3), 499-521.

Sheldon, K. M., \& McGregor, H. (2000). Extrinsic value orientation and the tragedy of the commons. Journal of Personality, 68 (2), 383-411 


\section{Appendices}

Appendix A: Some human values and their possible value-actions.

Table A1 presented a list of some human values and their possible value-actions that can be explored in the design of a study instrument for value measurement.

Table A: Some examples of value types and their possible behavioral actions

\begin{tabular}{|c|c|}
\hline Value type & Behavioral actions (value-actions) \\
\hline Health & $\begin{array}{l}\text { Routine medical check-up, dietary control, exercise regularly, proper hygiene, regular } \\
\text { sanitation, drug administrations, routine vaccination, avoid consuming harmful } \\
\text { products, abstain from drug abuse every, etc. }\end{array}$ \\
\hline Security & mploy guards, become sensitive and vigilant, share intelligence, etc. \\
\hline Nutrition & Routine meal, crop cultivation, animal rearing, etc. \\
\hline $\begin{array}{l}\text { Social and } \\
\text { political power }\end{array}$ & Accept leadership and responsibilities, etc. \\
\hline Family & Marri \\
\hline Biodi & $\begin{array}{l}\text { Biodiversity conservation (routine management and regeneration), biodiversity } \\
\text { utilization (usage, exploitation, processing), etc. }\end{array}$ \\
\hline Education & $\begin{array}{l}\text { Attend schools, habitual reading, perform assignments, attend lectures and practical, } \\
\text { conduct research, etc. }\end{array}$ \\
\hline Tradi & , new year, ceremonies, etc. \\
\hline Achic & trive 1 \\
\hline Personalities & Behave modestly, dress decent, keep prom \\
\hline Wealth & Business commitments, entrepreneurship, involvement in the workplace, etc. \\
\hline Autor & rive for political and social independence and freedom, et \\
\hline Politics & Contests for elections, voters an election, Campaign for an elec \\
\hline $\operatorname{Re}$ & larly, attend prayer meetings, prop \\
\hline Morality & $\begin{array}{l}\text { Establish ethical standards, promote an ethical standard, enforce ethical standards, } \\
\text { etc. }\end{array}$ \\
\hline Socialization & $\begin{array}{l}\text { Educates our child, accept and utilize technological innovation, interacts with } \\
\text { people, etc. }\end{array}$ \\
\hline Tech & Design and develop infrastructure, creates new ideas and innovations, etc. \\
\hline Language & 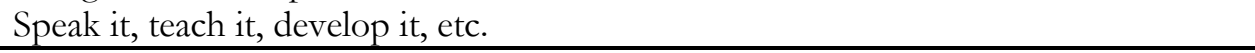 \\
\hline
\end{tabular}




\section{Kabiru's Value Survey Methodology}

Appendix B: Sample of the designed survey instrument

The samples of survey instruments presented here are not standard or have undergone validity and reliability checks, but are provided to serve as a guide upon which many other instruments can be designed.

Table B1: Sample of a questionnaire for some specific value-actions related to a value type

\begin{tabular}{|c|c|c|c|c|c|c|c|}
\hline \multicolumn{3}{|c|}{ Respond only to value types that relate to you as a HABITUAL ACTION in your LIFE } & \multicolumn{5}{|c|}{ Tick only ONE appropriate to your choice } \\
\hline Statement of impression & Value type & Behavioral actions (value-actions) & Year & Day & Week & $\begin{array}{l}\text { Daylight OR } \\
\text { Day-night }\end{array}$ & Day and night \\
\hline \multirow[t]{6}{*}{ Because of the values, I have for my } & \multirow[t]{6}{*}{ Health } & I go for a routine medical check-up about every ...... & & & & & \\
\hline & & I take regular exercise about every ..... & & & & & \\
\hline & & I observe proper hygiene about every ...... & & & & & \\
\hline & & I do regular sanitation about every ...... & & & & & \\
\hline & & I abstain from drug abuse about every ..... & & & & & \\
\hline & & I avoid harmful products about every ...... & & & & & \\
\hline \multirow[t]{3}{*}{ Because of the values, I have for the } & \multirow[t]{3}{*}{ Biodiversity } & I care for the biodiversity on every ...... & & & & & \\
\hline & & I conserve* it about every ..... & & & & & \\
\hline & & I manage** it about every ...... & & & & & \\
\hline \multirow[t]{3}{*}{ Because of the values, I have for the } & \multirow[t]{3}{*}{ Security } & I employ/adopt guards about every ...... & & & & & \\
\hline & & I become vigilant about every ...... & & & & & \\
\hline & & I share intelligence about every ...... & & & & & \\
\hline \multirow[t]{3}{*}{ Because of the values, I have for the } & \multirow[t]{3}{*}{ Morality } & I act with morality every ...... & & & & & \\
\hline & & I promote it every ...... & & & & & \\
\hline & & I enforce it every ...... & & & & & \\
\hline
\end{tabular}

*Conserving it signifies that I do not exploit any threatened species.

*Managing it signifies that I regenerate it, wisely exploit it while avoiding illegal cutting and pouching of plant and animal species respectively. 


\section{Kabiru's Value Survey Methodology}

Table B2: Sample of a questionnaire for specific material values.

\begin{tabular}{|c|c|c|c|c|c|c|c|c|c|c|}
\hline \multicolumn{3}{|c|}{ Respond only to items that relate to you as a HABITUAL ACTION in your LIFE } & \multicolumn{8}{|c|}{ Tick only ONE in each event appropriate to your choice } \\
\hline $\begin{array}{l}\text { Statement of value } \\
\text { impression }\end{array}$ & Value type & $\begin{array}{l}\text { Behavioral actions (value- } \\
\text { actions) }\end{array}$ & \multicolumn{5}{|c|}{ First (main) primary dependent variables } & \multicolumn{3}{|c|}{$\begin{array}{l}\text { First-ordered secondary } \\
\text { dependent variables }\end{array}$} \\
\hline & & & Year & Day & Week & $\begin{array}{l}\text { Daylight OR } \\
\text { Day-night }\end{array}$ & $\begin{array}{l}\text { Daylight \& } \\
\text { Day-night }\end{array}$ & $1-2$ times & $2-3$ times & 3-4 times \\
\hline \multirow{5}{*}{$\begin{array}{l}\text { Because of the medicinal } \\
\text { importance of }\end{array}$} & \multirow{5}{*}{$\begin{array}{l}\text { Balanite plant, } \\
\text { I use/give its parts } \\
\text { for management of }\end{array}$} & Pile about every ...... & & & & & & & & \\
\hline & & Malaria about every ...... & & & & & & & & \\
\hline & & Measles about every ..... & & & & & & & & \\
\hline & & Typhoid about every ..... & & & & & & & & \\
\hline & & Infections about every ..... & & & & & & & & \\
\hline \multirow{3}{*}{$\begin{array}{l}\text { Because of the nutritional } \\
\text { importance of }\end{array}$} & Maringa, & Soups about every ...... & & & & & & & & \\
\hline & I use it as food in & Drinks about every ..... & & & & & & & & \\
\hline & & Snacks about every ...... & & & & & & & & \\
\hline \multirow{3}{*}{$\begin{array}{l}\text { Because of the market } \\
\text { values of }\end{array}$} & \multirow[t]{3}{*}{ Mobile phones, we } & Produce them about every ...... & & & & & & & & \\
\hline & & Wholesale them about every ... & & & & & & & & \\
\hline & & Retail them every ..... & & & & & & & & \\
\hline \multirow{3}{*}{$\begin{array}{l}\text { Because of the economic } \\
\text { importance of }\end{array}$} & \multirow[t]{3}{*}{ Woody trees, I } & Exploits them about every ...... & & & & & & & & \\
\hline & & Process them about every . & & & & & & & & \\
\hline & & Sale them about every ...... & & & & & & & & \\
\hline
\end{tabular} \\ Preprints (urum.prepints.org)। NOT PEER-REVIEVED। Posted: 26 January 2021 \\ doi:10.20944/preprints201901.0107.v3}




\section{Kabiru's Value Survey Methodology}

Table B3: Sample of a summary sheet for value measurement per individual score

Instruction: Use figure B. Please score the following value practices as a HABITUAL ACTION in your life.

\begin{tabular}{|c|c|c|c|c|c|c|c|c|}
\hline & Value Practices & & Respo & ase coded & scales & & & Result \\
\hline $\begin{array}{l}\text { Value } \\
\text { items }\end{array}$ & Frequency of: & $\begin{array}{c}(\boldsymbol{F E R N})_{p} \\
(A)\end{array}$ & $\begin{array}{c}(\mathrm{FERN})_{s} \\
(\boldsymbol{B})\end{array}$ & $\begin{array}{c}(S E R N)_{s} \\
(C)\end{array}$ & $\begin{array}{c}(T E R N)_{s} \\
(D)\end{array}$ & $\begin{array}{c}(\text { FERN })_{s} \\
(E)\end{array}$ & $(\boldsymbol{R E R N})_{i}$ & $\begin{array}{c}V P S \\
\left(P I^{-1}\right)\end{array}$ \\
\hline Example & Attending hospital & 2 & 6 & 3 & $\mathrm{X}$ & $\mathrm{X}$ & 1.63 & 0.326 \\
\hline Example & Voluntary service & 3 & 6 & 6 & 2 & 3 & 2.6623 & 0.53246 \\
\hline VI-1 & Meals (Eating Habit) & & & & $\mathrm{X}$ & $\mathrm{X}$ & & \\
\hline VI-2 & Dietary control & & & & $\mathrm{X}$ & $\bar{X}$ & & \\
\hline VI-3 & $\begin{array}{ll}\begin{array}{l}\text { Routine } \\
\text { check-up }\end{array} & \\
\end{array}$ & & & & $\mathrm{X}$ & $\mathrm{X}$ & & \\
\hline VI-4 & $\begin{array}{l}\begin{array}{l}\text { Regular } \\
\text { exercise* }\end{array} \\
\end{array}$ & & & & & & & \\
\hline VI-5 & Sleeping habit & & & & & & & \\
\hline VI-6 & Alcoholism & & & & $\mathrm{X}$ & $\mathrm{X}$ & & \\
\hline VI-7 & Tobacco & & & & $\mathrm{X}$ & $\mathrm{X}$ & & \\
\hline VI-8 & Substance abuse & & & & $\mathrm{X}$ & $\mathrm{X}$ & & \\
\hline VI-9 & Carbonated drinks & & & & $\mathrm{X}$ & $\mathrm{X}$ & & \\
\hline VI-10 & Tea/Coffee drinks & & & & $\mathrm{X}$ & $\mathrm{X}$ & & \\
\hline VI-11 & Coldwater drinks & & & & $\mathrm{X}$ & $\mathrm{X}$ & & \\
\hline VI-12 & Cola nut chews & & & & $\mathrm{X}$ & $\mathrm{X}$ & & \\
\hline VI-13 & Sugary food intake & & & & $\mathrm{X}$ & $\mathrm{X}$ & & \\
\hline VI-14 & $\begin{array}{l}\text { Fatty/oily food } \\
\text { intake }\end{array}$ & & & & $\mathrm{X}$ & $\mathrm{X}$ & & \\
\hline
\end{tabular}

*EXCLUDE cooking but INCLUDES mowing, bicycling, gyms, house cleanings, manual labors, etc. 


\section{Kabiru's Value Survey Methodology}

[A]

[0]

Never at all

About every year

About every month

About every week

About every daylight

OR day-night

About every day and night
[B]

$[\mathrm{C}]$

$[\mathrm{D}]$

[E]

Figure B: Sample of a structured questionnaire for different value measurement. In this questionnaire design, the multi-factors and their frequencies were organized and ranked. The responses can be captured simply by the assigned event's rank numbers for any particular practice frequency of any appropriate factor. Table 3 is a simple guide. 
Kabiru's Value Survey Methodology

Appendix C: Derivation of equation 3

$$
\begin{aligned}
& \mathrm{AVI}=\left\{\begin{array}{l}
\left(\frac{(\mathrm{RERN})_{1}}{5} \times \frac{\mathrm{na}_{1}}{\mathrm{Na}}\right)+\left(\frac{(\mathrm{RERN})_{2}}{5} \times \frac{\mathrm{na}_{2}}{\mathrm{Na}}\right)+\left(\frac{(\mathrm{RERN})_{3}}{5} \times \frac{\mathrm{na}_{3}}{\mathrm{Na}}\right)+ \\
\left(\frac{(\mathrm{RERN})_{4}}{5} \times \frac{\mathrm{na}_{4}}{\mathrm{Na}}\right)+\left(\frac{(\mathrm{RERN})_{5}}{5} \times \frac{\mathrm{na}_{5}}{\mathrm{Na}}\right)+\cdots+\left(\frac{(\mathrm{RERN})_{\mathrm{i}}}{5} \times \frac{\mathrm{na}_{\mathrm{i}}}{\mathrm{Na}}\right)
\end{array}\right\} \times \frac{\mathrm{Na}}{\mathrm{Np} \ldots \ldots \ldots} \\
& =\left\{\left(\frac{(\operatorname{RERN} \times \text { na })_{4}+(\operatorname{RERN} \times \text { na })_{5}+\cdots+(\operatorname{RERN} \times \text { na })_{i}}{5 \times \mathrm{Na}}\right)\right\} \times \frac{\mathrm{Na}}{\mathrm{Np}} \ldots \ldots \ldots . \\
& (\operatorname{RERN} \times \text { na })_{1}+(\operatorname{RERN} \times \text { na })_{2}+(\operatorname{RERN} \times \text { na })_{3}+ \\
& =\frac{(\operatorname{RERN} \times \text { na })_{4}+(\operatorname{RERN} \times \text { na })_{5}+\cdots+(\operatorname{RERN} \times \text { na })_{\mathrm{i}}}{5 \times \mathrm{Np}} . \\
& =\sum_{1}^{\mathrm{i}}\left(\frac{(\mathrm{RERN} \times \mathrm{na})_{\mathrm{i}}}{5 \times \mathrm{Np}}\right) \\
& =\frac{1}{5 \times \mathrm{Np}} \sum_{1}^{\mathrm{i}}(\mathrm{RERN} \times \mathrm{na})_{\mathrm{i}}
\end{aligned}
$$

\section{Appendix D: Graphical Abstract}

A graphical abstract for Kabiru's value survey (KVS) methodology is presented here to provide a reader with the summarized picture of what the proposal is all about. 
Kabiru's Value Survey Methodology

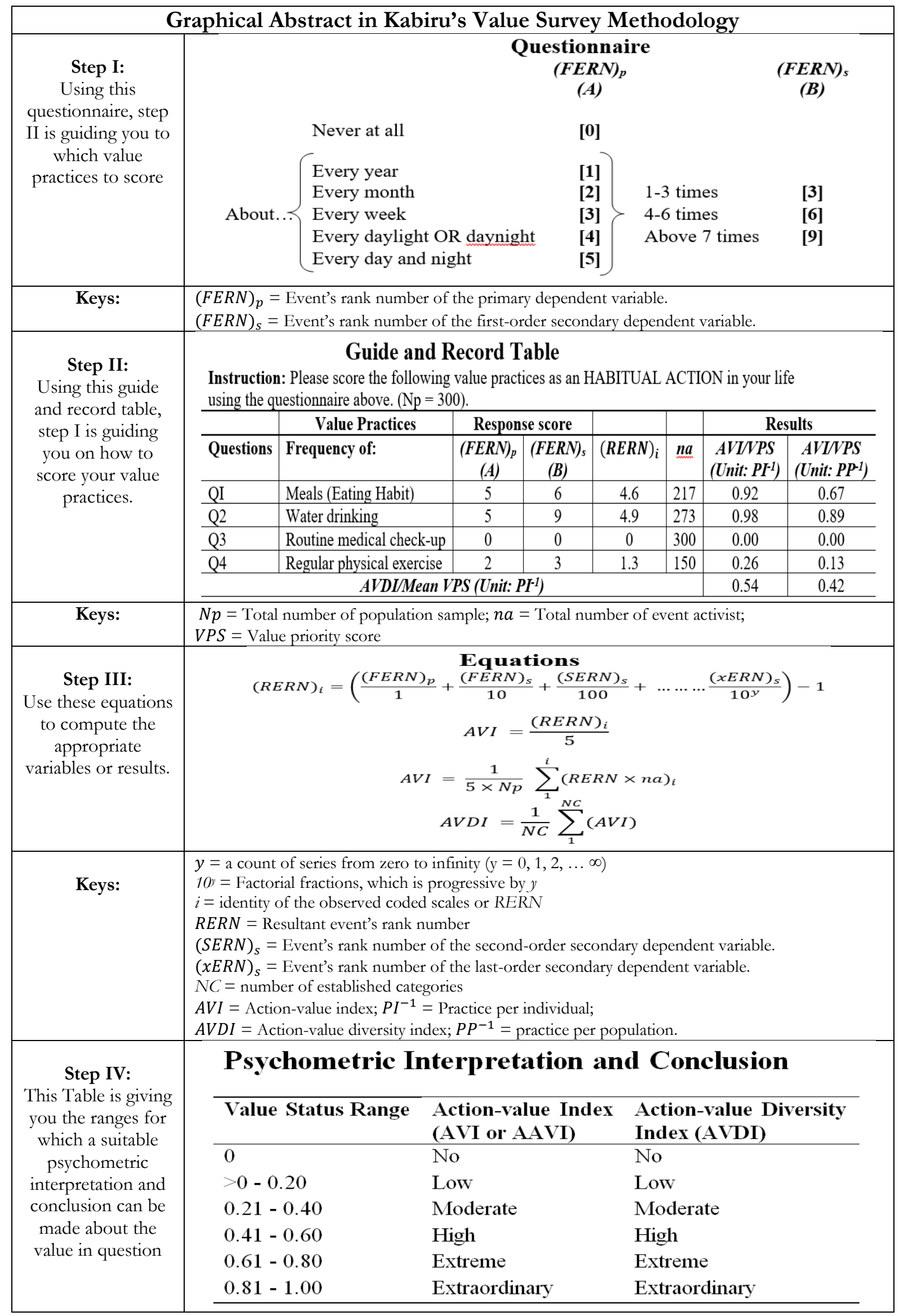

